\title{
Aspectos estratégicos, estruturais e relacionais de três cadeias de suprimentos automotivas
}

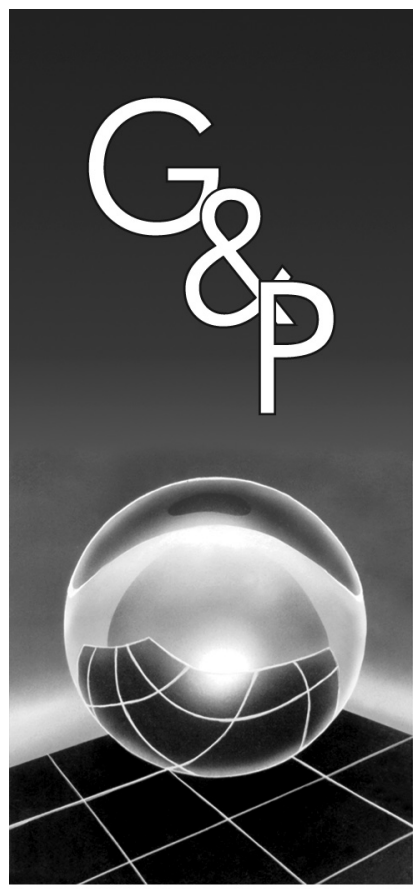

\author{
Aline Lamon Cerra \\ Jonas Lucio Maia \\ Alceu Gomes Alves Filho
}

\section{Resumo}

Este artigo tem por objetivo identificar algumas das principais diferenças estruturais, relacionais e de orientação estratégica das cadeias brasileiras produtoras de motores, bem como sinalizar fatores decorrentes ou responsáveis por tais diferenças. São estudadas e comparadas as estruturas e as relações entre empresas de cadeias "comandadas" por três montadoras de motores. Foram utilizados estudos de caso em três montadoras e oito fornecedores atuantes no primeiro elou segundo nível de suas cadeias de suprimentos. Embora as montadoras estejam inseridas em cadeias com configurações estruturais diferentes, e adotem padrões de relacionamento distintos, suas ações para gestão da cadeia de suprimentos se encontram estrategicamente alinhadas. Desta forma, mesmo ocorrendo sobreposição entre as cadeias, pela presença de fornecedores comuns, as montadoras conseguem efetivamente utilizá-las de forma a aumentar sua competitividade. $O$ trabalho ainda indica algumas tendências gerais, como a da terceirização e a existência de poucos níveis hierárquicos, com os fornecedores no segundo nível produzindo componentes menos sofisticados tecnologicamente.

Palavras-chave: Gestão da cadeia de suprimentos. Estratégia. Indústria automobilística. Motores para automóveis.

\section{Introdução}

A intensificação da competição no mercado automotivo brasileiro e internacional revelou às montadoras instaladas no Brasil necessidades urgentes de melhorias nos padrões locais de qualidade e produtividade.

No contexto da produção de automóveis, o motor constitui um sistema considerado estratégico para a competitividade das montadoras, sendo composto por um grande número de componentes (especialmente no segmento metal-mecânico). Frente a esta relevância e diversidade de componentes, a estratégia de suprimentos das montadoras de motores exerce papel importante para as operações no setor.

O setor de autopeças é composto por vários segmentos heterogêneos e o padrão de concorrência em cada segmento apresenta especificidades, como características técnicas do produto, número de fabricantes e nível de verticalização das montadoras nos itens de cada segmento, dentre outras (QUADROS et al., 2000). Além disto, conforme apresenta Cerra (2005), os diversos fornecedores de autopeças possuem capacidades tecnológicas diferentes, o que os torna diferenciadamente aptos a realizarem melhorias e inovações nos produtos que fornecem.

Considerando a importância das estratégias de suprimentos das montadoras de motores para a competitividade dessas empresas, e a heterogeneidade verificada em suas bases de fornecedores, este artigo tem por objetivo identificar eventuais diferenças estruturais, relacionais e de orientação estratégica das diversas cadeias brasileiras produtoras de motores, bem como sinalizar eventuais fatores decorrentes ou responsáveis por tais diferenças. Desse modo, pretende-se investigar como as montadoras procuram gerenciar suas cadeias de forma a viabilizar suas prioridades estratégicas. Em particular, procura-se discutir em que medida as estratégias das montadoras afetam as estruturas e relações nas cadeias de suprimentos e, por outro lado, como estruturas e relações condicionam suas estratégias. Para isso serão estudadas e comparadas as estruturas e algumas das relações entre empresas no interior de três cadeias, por meio de estudos de caso.

A gestão da cadeia de suprimentos, base teórica da análise aqui proposta, considera que a competição no 
mercado ocorre entre cadeias produtivas e não apenas entre empresas (CHRISTOPHER, 1992). Assim, abrange a coordenação de atividades e processos não apenas dentro de uma organização, mas entre todas as que compõem a cadeia de suprimentos, partindo do pressuposto de que há benefícios significativos a serem ganhos ao se dirigir estrategicamente a cadeia em direção à satisfação dos clientes finais.

Este trabalho apresenta, a seguir, a literatura a respeito da gestão da cadeia de suprimentos. Na sequiência são apresentados o método da pesquisa e a análise dos casos. Finalizando, algumas conclusões são indicadas, assim como são apresentadas possibilidades para futuras pesquisas.

\section{Conceitos e pressupostos da gestão da cadeia de suprimentos (supply chain management)}

Antes de prosseguir o estudo da gestão da cadeia de suprimentos (GCS), é necessário definir qual o objeto gerido por tais práticas e conceitos. Para Chopra e Meindl (2003), uma cadeia de suprimentos engloba todos os estágios (clientes, varejistas, distribuidores, fabricantes e fornecedores) envolvidos, direta ou indiretamente, no atendimento de um pedido ao cliente. Pode ser vista, segundo Lummus et al. (1998), como uma rede de entidades que abrange todo o fluxo de materiais e informações.

O interesse pela gestão da cadeia de suprimentos se intensificou a partir da década de 90, devido principalmente: à maior verticalização e especialização das empresas; ao aumento da competitividade nacional e internacional; e ao diferencial competitivo obtido por meio da GCS, que proporciona, dentre outras vantagens, reduções de custos e maior agilidade nas entregas (LUMMUS; VOKURKA, 1999).

Desta forma, a GCS é um conceito desenvolvido com enfoque holístico, que gerencia além das fronteiras da empresa, reconhecendo que há benefícios significativos a serem ganhos ao tentar dirigir estrategicamente toda uma cadeia em direção à satisfação dos clientes finais (SLACK et al., 1997; LUMMUS et al., 1998).

Assim, a GCS pode ser definida como

"[...] a integração dos principais processos que gerenciam os fluxos bidirecionais de materiais, informações e financeiros no âmbito intraempresa e entre empresas participantes da cadeia de suprimentos até atingir os consumidores finais, cujo objetivo principal é agregar valor aos acionistas e aos clientes ao longo destes processos [...]" (PEDROSO, 2002, p. 21).
Segundo Alves Filho et al. (2004), o corpo de literatura acerca da GCS tem se desenvolvido, mas ainda se encontra em fase de consolidação. A base teórica do conceito, tendo contemplado contribuições de diversas correntes de pensamento, fundamenta-se sobre uma série de pressupostos que se inter-relacionam, podendo ser assim sintetizados:

a) competição entre cadeias de suprimentos: a competição no mercado ocorre no nível das cadeias e não apenas no nível das empresas (CHRISTOPHER, 1992);

b) coordenação da cadeia de suprimentos: para que haja coordenação da cadeia, todos os estágios devem realizar ações que, em conjunto, aumentem os lucros da cadeia de suprimentos. Isto requer que cada estágio leve em consideração o impacto que suas ações exercem sobre outros estágios (CHOPRA; MEINDL, 2003);

c) alinhamento das estratégias das empresas da cadeia de suprimentos: proporciona habilidades para melhoria de desempenho da empresa desde que haja clareza na visão de seu papel na cadeia de suprimentos e realização conjunta de atividades de aprendizado e inovação. Este alinhamento estratégico pode ser analisado sob dois prismas distintos: a) o alinhamento entre as estratégias competitivas das empresas posicionadas nos elos das cadeias, de forma que tais estratégias sejam compatíveis entre as empresas e voltadas para a satisfação do cliente final da cadeia; e b) o alinhamento entre as estratégias competitivas das companhias e as estratégias que estas adotam para gerir suas cadeias de suprimentos. Neste último sentido, a estratégia da cadeia de suprimentos deve ter as mesmas metas da estratégia competitiva, além de propiciar a construção de capacidades (em GCS) que viabilizem a forma de competir empreendida pela companhia (CHOPRA; MEINDL, 2003);

d) cooperação na cadeia de suprimentos: faz-se necessária efetiva cooperação entre as firmas envolvidas no fornecimento do produto final (LAMMING, 1993). As parcerias representam a forma de atingir esta cooperação, e segundo Lamming apud Slack et al. (1997, p. 433), podem ser definidas como "o compartilhamento de riscos e recompensas de tecnologia e inovação, levando à redução de custos, ao aprimoramento na entrega e na qualidade, e à ampliação de vantagem competitiva sustentada";

e) outsourcing: pode ser definido, em linhas gerais, como a transferência da produção de mercadorias e serviços que estava sendo desempenhada internamente para a parte externa da empresa (ELLRAM; BILLINGTON, 2000). Escolhendo se concentrar em suas principais competências, as empresas optam 
por repassar determinadas atividades produtivas aos seus fornecedores (atuais ou novos), trazendo importantes implicações para as cadeias nas quais estão inseridas;

f) fluxo bidirecional de produtos e informações: existência de um fluxo bidirecional de produtos (materiais e serviços) e informações entre todas as empresas pertencentes à cadeia de suprimentos (COOPER et al., 1997);

g) redução do número de fornecedores: o número de fornecedores tende a diminuir (TAN, 2002) e eles passam a ser hierarquizados de acordo com o nível que ocupam na cadeia (ELLRAN, 1991 apud MIRANDA, 2002). Pires (2004) indica a tendência de reestruturação e consolidação da base de fornecedores e clientes, com o objetivo de definir um conjunto de empresas (fornecedores e clientes) com os quais deseja construir parcerias;

h) relações de longo prazo e baseadas em confiança: segundo Christopher (1992), ao fazer a seleção de fornecedores e também ao procurar os critérios para a redução da base de fornecimento, a organização deve buscar aquelas empresas que sejam capazes de aceitar o desenvolvimento de um relacionamento de longo prazo com base na confiança mútua;

i) desenvolvimento de fornecedores: as empresas têm investido no desenvolvimento de fornecedores, tarefa que, segundo Handfield et al. (2000), abrange qualquer atividade que um comprador empreende no sentido de melhorar as capacidades de desempenho de um fornecedor para satisfazer as suas necessidades de compra, tanto no curto prazo como no longo prazo. Com freqüência são feitas avaliações formais dos fornecedores e muitas empresas têm estabelecido programas de treinamentos para seus fornecedores para auxiliá-los a alcançarem metas de desempenho superiores; e

j) $P \& D$ e desenvolvimento de produtos em conjunto: outra prática que tem se expandido no contexto da GCS é o envolvimento conjunto das empresas em P\&D (ELLRAN, 1991 apud MIRANDA, 2002) e o envolvimento de fornecedores no processo de desenvolvimento e fabricação de novos produtos (TAN, 2002).

A Figura 1 sintetiza os principais pressupostos da GCS agrupados em quatro subconjuntos relacionados, respectivamente: a) ao ambiente competitivo; b) ao alinhamento estratégico das organizações e à repartição dos ganhos; c) à estrutura da cadeia; e d) às relações entre as empresas da cadeia.

$\mathrm{O}$ primeiro subconjunto de pressupostos se refere à maneira que as companhias e pesquisadores percebem o ambiente competitivo. Conforme mencionado, para Christopher (1992), tal ambiente passou por um processo

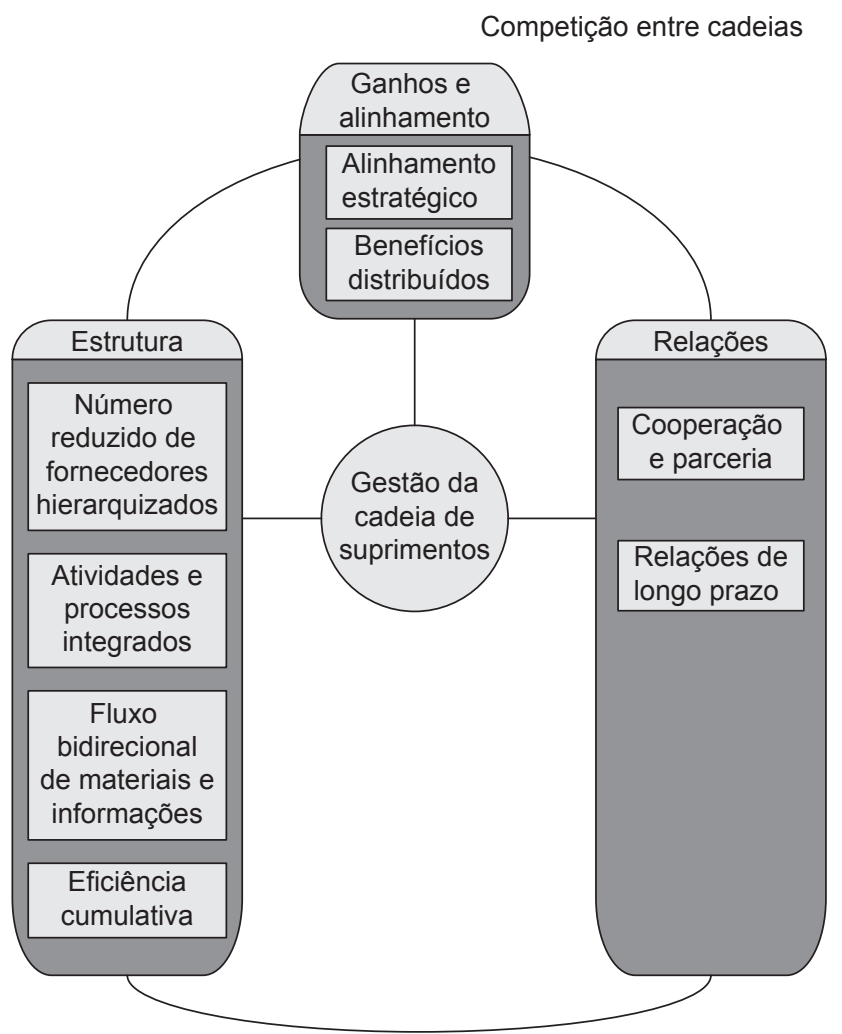

Figura 1. Principais pressupostos da gestão da cadeia de suprimentos (ALVES FILHO et al., 2004).

de reestruturação, de forma que a competição ocorre entre cadeias inteiras, e não mais entre empresas isoladas.

O segundo grupo de pressupostos deriva do primeiro. Se agora a competição ocorre entre cadeias inteiras, as companhias devem ter suas estratégias alinhadas, de forma que ações individuais gerem ganhos para toda a cadeia. A contrapartida do alinhamento estratégico seria uma distribuição de ganhos equânime entre as empresas, de acordo com os esforços e investimentos feitos por cada uma.

O terceiro subconjunto contempla aspectos relativos à estrutura, isto é, o papel que cada companhia e unidade produtiva devem desempenhar dentro das cadeias. Ele inclui a existência de um pequeno número de fornecedores hierarquizados, a integração de processos e atividades através da cadeia (ex. desenvolvimento de produtos, $\mathrm{P} \& \mathrm{D}$ ), a ocorrência de um fluxo bidirecional eficiente de materiais e informação, e os esforços que cada companhia realiza de forma a reduzir sua própria complexidade (reduzindo assim, a complexidade da cadeia como um todo).

O quarto grupo se refere às relações entre as companhias dentro da cadeia de suprimentos. Ele lida com o estabelecimento de relações cooperativas e de longo prazo, assim como parcerias entre as empresas.

Esta seção buscou realizar uma síntese teórica a respeito da GCS e seus principais pressupostos contemplados. 
Esta síntese fornecerá os subsídios para a realização da análise dos casos a seguir descritos.

\section{Método de Pesquisa}

Para a consecução dos objetivos desta pesquisa, foram realizados diversos estudos de caso em empresas das cadeias produtoras de motores.

Segundo Lazzarini (1997), os métodos denominados qualitativos, dentre os quais se tem os estudos de caso, caracterizam-se por foco maior na compreensão dos fatos do que propriamente na sua mensuração.

Os estudos de caso foram realizados por meio de entrevistas semi-estruturadas com a utilização de um questionário formulado a partir da revisão da literatura, em três montadoras de motores e oito fornecedores. Nestas empresas, as pessoas entrevistadas foram diretores industriais e gerentes de compras e de produção.

As questões foram subdivididas em duas partes, a primeira abordando a estrutura da cadeia produtiva de cada empresa, e a segunda envolvendo as relações entre as empresas que a compõe.

No que tange à posição na cadeia das empresas estudadas, os casos foram realizados em três montadoras de motores para automóveis, quatro fornecedores de primeiro nível, e em dois fornecedores que, além de fornecerem diretamente às montadoras, podem também ser considerados fornecedores de segundo nível delas, na medida em que também fornecem componentes para empresas de autopeças fornecedoras diretas das montadoras. Além dessas empresas, foram estudados também dois fornecedores de segundo nível.

Apenas uma das empresas de primeiro nível e uma de segundo nível, dentre os fornecedores estudados, possuem capital de origem nacional, sendo as demais subsidiárias de empresas multinacionais. Além das diferenças quanto à origem, os fornecedores se diferenciam quanto ao porte, localização e papéis desempenhados nas cadeias.

Foram realizadas, em média, duas entrevistas em cada empresa da amostra, incluindo questões que envolviam tanto os clientes quanto os fornecedores, de forma a cobrir as cadeias de suprimentos por inteiro.

\section{Estudos de caso}

Esta seção apresenta a descrição e contextualização das empresas, e a seguir são apresentados os dados referentes aos aspectos estruturais, relacionais e estratégicos da gestão da cadeia de suprimentos em montadoras e fornecedores.

\subsection{Descrição das empresas}

A Figura 2 apresenta as empresas das cadeias estudadas e as relações de fornecimento que ocorrem entre elas.

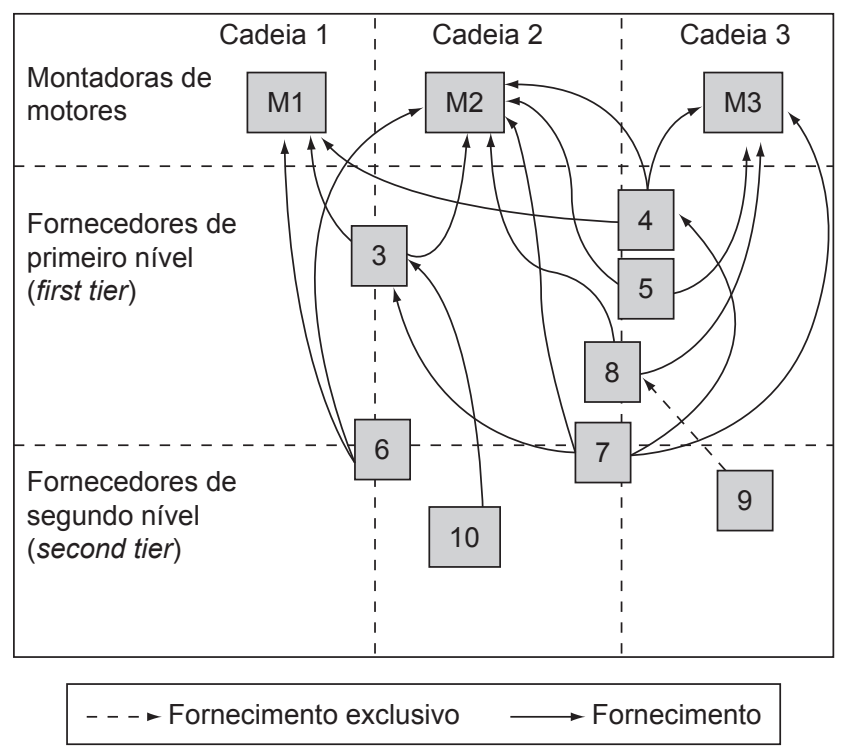

Figura 2. Relações de fornecimento entre as empresas das cadeias de suprimentos.

A montadora 1 produz motores 1.0 a $1.8(1000$ a 1800 cilindradas), e também uma linha de modelos de motores específicos de sua marca, composta por motores $1.0,1.3$ e 1.6 .

Os produtos fabricados pela montadora 2 são motores 1.0 a 1.8 , e também uma linha de motores 2.0 a 2.4 . Deve-se mencionar também, que a montadora 2 fornece motores 1.8 para a montadora de automóveis do grupo ao qual a montadora 1 pertence.

Os produtos fabricados na planta estudada da montadora 3 são motores 1.0 a 1.6, compreendendo 26 modelos de motores.

Alguns dos fornecedores são exclusivos da montadora 2 (embora possam fornecer a outras, exceto a montadora 3), e portanto fazem parte da cadeia 2. Alguns fornecedores estudados fornecem tanto para a montadora 2 quanto para a montadora 3, e portanto fazem parte das duas cadeias estudadas. Há ainda um fornecedor que pertence às três cadeias estudadas, a empresa 4 , mas vale ressaltar que esta empresa fornece apenas peças para o mercado de reposição da montadora 1.

As empresas 4 e 5, embora forneçam para as montadoras 2 e 3 , mantêm a montadora 3 como cliente principal, e por isso encontram-se posicionadas mais à direita da figura. Do mesmo modo, a empresa 7 está mais voltada à cadeia 2 . Diferença é encontrada na empresa 8 , situada no centro da figura por pertencer às duas cadeias (2 e 3 ) igualmente.

Vale ressaltar que a empresa 6, embora forneça componentes tanto às montadoras de motores quanto às empresas de autopeças, não os fornece para nenhum fornecedor de primeiro nível da amostra aqui estudada. Ela pertence às cadeias 1 e 2, assim como a empresa 3. 
De forma a permitir a análise cruzada entre os diversos casos estudados, optou-se aqui por apresentar os resultados de forma tabular e não em texto corrente. A Tabela 1 sintetiza as características gerais dos fornecedores estudados, que serão descritas na seção a seguir.

\subsection{Descrição das cadeias de suprimentos: montadoras de motores}

A montadora 1 faz internamente o bloco dos motores, virabrequim e cabeçotes. Os demais componentes são terceirizados. A fundição dos blocos é feita em um fornecedor pertencente ao grupo econômico da montadora.

A montadora 2 terceirizou a usinagem dos componentes para motores, mas ainda faz internamente alguns componentes fundidos como: bloco do motor, cabeçote, árvore de manivelas (virabrequim), eixo comando, carcaça do eixo comando e biela. Terceirizar a fundição de tais produtos é uma das metas desta montadora, e supõe-se que em um período de dois anos estes componentes deverão estar sendo produzidos por fornecedores.

Já a montadora 3 pode ser considerada como uma das montadoras de motores, dentre as instaladas no Brasil, com maior nível de terceirização na fabricação dos componentes principais. Desde o início da produção da fábrica, faz a usinagem dos blocos dos motores internamente e terceiriza os demais componentes, inclusive a fundição.

A montadora 1 possui quatro tipos de fornecimento: a) direto, quando os fornecedores lhes enviam as peças requisitadas; b) depósitos situados próximos à planta da montadora, onde 5 de seus fornecedores mantêm estoques; c) VMI (vendor managed inventory), por meio do qual 8 fornecedores mantêm e gerenciam estoques de materiais dentro da planta da montadora; e d) através do centro de recebimento de cargas, localizado em outro estado e que é administrado por uma empresa terceirizada. Neste centro de recebimento, as cargas são recebidas de diversos fornecedores e consolidadas para envio à montadora de motores.
As montadoras 2 e 3 estão localizadas próximas de seus fornecedores principais. Em decorrência disto, a montadora 3 optou por sistema de fornecimento em milk run, retirando diariamente em seus fornecedores a quantidade de peças necessárias.

Similarmente à empresa 1 , a montadora 2 também adota a prática do VMI, com fornecedores instalados e gerenciando estoques dentro da planta. Tal prática traz vantagens para as montadoras, que se eximem da necessidade de gestão destes estoques, bem como não necessitam arcar com os custos de capital empatado nos mesmos.

As Tabelas 2 e 3 sintetizam, respectivamente, as características relevantes das cadeias de suprimentos das montadoras de motores e também das relações entre empresas no interior delas:

\subsection{Descrição das cadeias de suprimentos: fornecedores}

As Tabelas 4 e 5 sintetizam as características referentes aos fornecedores, tanto no que tange à estrutura das cadeias de suprimentos quanto às relações entre empresas no interior delas.

\section{Análise das cadeias de suprimentos}

A partir da metade dos anos 90, as montadoras ampliaram significativamente seu mix de motores, o que implicou principalmente em (ALVES FILHO et al., 2005): a) esforços de desenvolvimento de produtos; b) adaptações e mudanças nas linhas de produção e montagem, incluídos aqui movimentos de terceirização; e c) mudanças na cadeia de suprimentos e na coordenação de fornecedores.

Os estudos de caso foram conduzidos em três cadeias de suprimentos (cadeia 1, cadeia 2 e cadeia 3), comandadas, respectivamente, pelas montadoras 1,2 e 3 .

As cadeias apresentam poucos níveis hierárquicos, tendo no segundo nível de suprimentos, empresas fornece-

Tabela 1. Características gerais dos fornecedores estudados.

\begin{tabular}{|c|c|c|c|c|c|c|c|c|}
\hline & Empresa 3 & Empresa 4 & Empresa 5 & Empresa 8 & Empresa 6 & Empresa 7 & Empresa 9 & Empresa 10 \\
\hline Fornecimento & $1^{\circ}$ nível & $1^{\circ}$ nível & $1^{\circ}$ nível & $1^{\circ}$ nível & $1^{\circ}$ e $2^{\circ}$ nível & $1^{\circ}$ e $2^{\circ}$ nível & $2^{\circ}$ nível & $2^{\circ}$ nível \\
\hline Capital & Estrangeiro & Estrangeiro & Nacional & Estrangeiro & Estrangeiro & Estrangeiro & Nacional & Estrangeiro \\
\hline Segmento & Eletrônico & $\begin{array}{l}\text { Metal- } \\
\text { mecânico }\end{array}$ & $\begin{array}{l}\text { Metal- } \\
\text { mecânico }\end{array}$ & $\begin{array}{l}\text { Metal- } \\
\text { mecânico }\end{array}$ & $\begin{array}{l}\text { Metal- } \\
\text { mecânico }\end{array}$ & $\begin{array}{l}\text { Metal- } \\
\text { mecânico }\end{array}$ & $\begin{array}{l}\text { Metal- } \\
\text { mecânico }\end{array}$ & Eletrônico \\
\hline $\begin{array}{l}\text { Principais } \\
\text { produtos }\end{array}$ & $\begin{array}{l}\text { Baterias, } \\
\text { bombas, } \\
\text { módulos e } \\
\text { filtros de } \\
\text { combustí- } \\
\text { vel, injetores, } \\
\text { tecnologia } \\
\text { flex fuel, etc. }\end{array}$ & $\begin{array}{l}\text { Diversos } \\
\text { modelos de } \\
\text { embreagens. }\end{array}$ & $\begin{array}{l}\text { Blocos de } \\
\text { motores, } \\
\text { cabeçotes, } \\
\text { bielas, câm- } \\
\text { bios, cole- } \\
\text { tores, dentre } \\
\text { outros. }\end{array}$ & $\begin{array}{l}\text { Pistões e } \\
\text { cilindros de } \\
\text { alumínio. }\end{array}$ & $\begin{array}{l}\text { Câmbios, } \\
\text { chassis, } \\
\text { suspensões } \\
\text { cárter de óleo } \\
\text { e componen- } \\
\text { tes agregados } \\
\text { do motor. }\end{array}$ & $\begin{array}{l}\text { Molas para } \\
\text { embreagens } \\
\text { e molas para } \\
\text { motores. }\end{array}$ & $\begin{array}{l}\text { Retira os } \\
\text { refugos da } \\
\text { empresa } 8, \\
\text { faz a fusão, } \\
\text { e retorna } \\
\text { o material } \\
\text { na forma } \\
\text { líquida. }\end{array}$ & $\begin{array}{l}\text { Vários } \\
\text { modelos } \\
\text { de came de } \\
\text { aceleração, } \\
\text { válvulas bor- } \\
\text { boleta, etc. }\end{array}$ \\
\hline
\end{tabular}


Tabela 2. Estrutura das cadeias de suprimentos das montadoras de motores.

\begin{tabular}{|c|c|c|c|}
\hline & Montadora 1 & Montadora 2 & Montadora 3 \\
\hline Clientes & $\begin{array}{l}\text { A montadora de automóveis do } \\
\text { grupo ao qual pertence }\end{array}$ & $\begin{array}{l}\text { A montadora de automóveis do } \\
\text { grupo ao qual pertence, além da } \\
\text { montadora de automóveis do } \\
\text { grupo da montadora } 1\end{array}$ & $\begin{array}{l}\text { A montadora de automóveis do } \\
\text { grupo ao qual pertence }\end{array}$ \\
\hline \multirow[t]{2}{*}{ Fornecedores diretos } & 80 fornecedores & 100 fornecedores & 130 fornecedores \\
\hline & $\begin{array}{l}\text { Pretende concentrar os componen- } \\
\text { tes terceirizados em um número } \\
\text { menor de fornecedores }\end{array}$ & $\begin{array}{l}\text { Pretende concentrar os } \\
\text { componentes terceirizados em } \\
\text { um número menor de fornece- } \\
\text { dores }\end{array}$ & $\begin{array}{l}\text { O número total de fornecedores } \\
\text { vem aumentando nos últimos } \\
\text { anos }\end{array}$ \\
\hline $\begin{array}{l}\text { Número de fornecedores } \\
\text { por componente adquirido } \\
\text { externamente }\end{array}$ & $\begin{array}{l}\text { Possui um fornecedor para cada } \\
\text { componente que adquire externa- } \\
\text { mente }\end{array}$ & Idem a montadora 1 & $\begin{array}{l}\text { Possui dois fornecedores por } \\
\text { componente terceirizado, mas } \\
\text { há casos em que existem três } \\
\text { ou mesmo um }\end{array}$ \\
\hline $\begin{array}{l}\text { Porte dos principais } \\
\text { fornecedores }\end{array}$ & $\begin{array}{l}\text { Cerca de } 80 \text { a } 90 \% \text { dos fornecedo- } \\
\text { res são empresas de grande e médio } \\
\text { porte, quase todos empresas multi- } \\
\text { nacionais }\end{array}$ & Idem a montadora 1 & $\begin{array}{l}\text { Possui muitos fornecedores de } \\
\text { médio e grande porte, mas há } \\
\text { também empresas pequenas, } \\
\text { geralmente de capital nacional. } \\
\text { Dos } 130 \text { fornecedores, cerca de } \\
65 \% \text { são empresas nacionais }\end{array}$ \\
\hline Fornecedores exclusivos & $\begin{array}{l}\text { Não possui fornecedores exclusi- } \\
\text { vos, embora seja o cliente principal } \\
\text { de alguns }\end{array}$ & Idem a montadora 1 & $\begin{array}{l}\text { Possui fornecedores quase } \\
\text { exclusivos, destinando à mon- } \\
\text { tadora } 3 \text { cerca de } 90 \% \text { de seu } \\
\text { volume total de produção }\end{array}$ \\
\hline
\end{tabular}

Tabela 3. Relações entre empresas nas cadeias de suprimentos das montadoras.

\begin{tabular}{|c|c|c|}
\hline & Montadora 2 & Montadora 3 \\
\hline $\begin{array}{l}\text { Seleção de fornecedores } \\
\text { (critérios considerados em } \\
\text { ordem de importância para a } \\
\text { montadora) }\end{array}$ & $\begin{array}{l}\text { Seleciona fornecedores com base Idem a montadora } 1 \\
\text { em critérios de qualidade e capaci- } \\
\text { dade tecnológica, seguidos de pre- } \\
\text { ços mais baixos }\end{array}$ & $\begin{array}{l}\text { Seleciona fornecedores com base em } \\
\text { preço, seguido de qualidade e capa- } \\
\text { cidade tecnológica }\end{array}$ \\
\hline Avaliação de fornecedores & $\begin{array}{l}\text { Avalia fornecedores ativos de acor- Idem a montadora } 1 \\
\text { do com o cumprimento de normas } \\
\text { de qualidade, por meio de audito- } \\
\text { rias, e os classifica de acordo com } \\
\text { tais critérios }\end{array}$ & Idem a montadora 1 \\
\hline $\begin{array}{l}\text { Desenvolvimento de } \\
\text { fornecedores }\end{array}$ & $\begin{array}{l}\text { Raros os casos de desenvolvimento Idem a montadora } 1 \\
\text { de fornecedores }\end{array}$ & $\begin{array}{l}\text { A montadora desenvolveu um con- } \\
\text { junto de fornecedores }\end{array}$ \\
\hline $\begin{array}{l}\text { Relações com outros níveis da } \\
\text { cadeia de suprimentos }\end{array}$ & $\begin{array}{l}\text { A montadora se relaciona apenas Idem a montadora } 1 \\
\text { com clientes e fornecedores dire- } \\
\text { tos. } \\
\text { Pode intervir em alguma nego- } \\
\text { ciação entre um fornecedor direto } \\
\text { com outro de segundo nível de su- } \\
\text { primento, de modo a facilitar e/ou } \\
\text { agilizar uma dada transação }\end{array}$ & $\begin{array}{l}\text { Relaciona-se apenas com clientes e } \\
\text { fornecedores diretos. Exceção ocorre } \\
\text { quando compra materiais de um for- } \\
\text { necedor de segundo nível e entrega } \\
\text { para um fornecedor de primeiro ní- } \\
\text { vel fazer a usinagem e a montagem. } \\
\text { Pode intervir em alguma negociação } \\
\text { entre um fornecedor direto com ou- } \\
\text { tro de segundo nível }\end{array}$ \\
\hline
\end{tabular}

doras de produtos menos sofisticados tecnologicamente, que não possuem contato direto com a montadora.

Uma exceção pode ser verificada na montadora 3 , que compra componentes de um fornecedor de segundo nível e os repassa para outro fornecedor (de primeiro nível) fazer a usinagem e a montagem do módulo.
Podem ainda ocorrer casos em que a montadora atua diretamente em seus fornecedores não imediatos para obter ganhos em prazos de entrega, preços, ou mesmo melhorias na qualidade dos produtos.

Os estudos demonstraram que essas montadoras apresentam diferentes níveis de terceirização na fabricação 


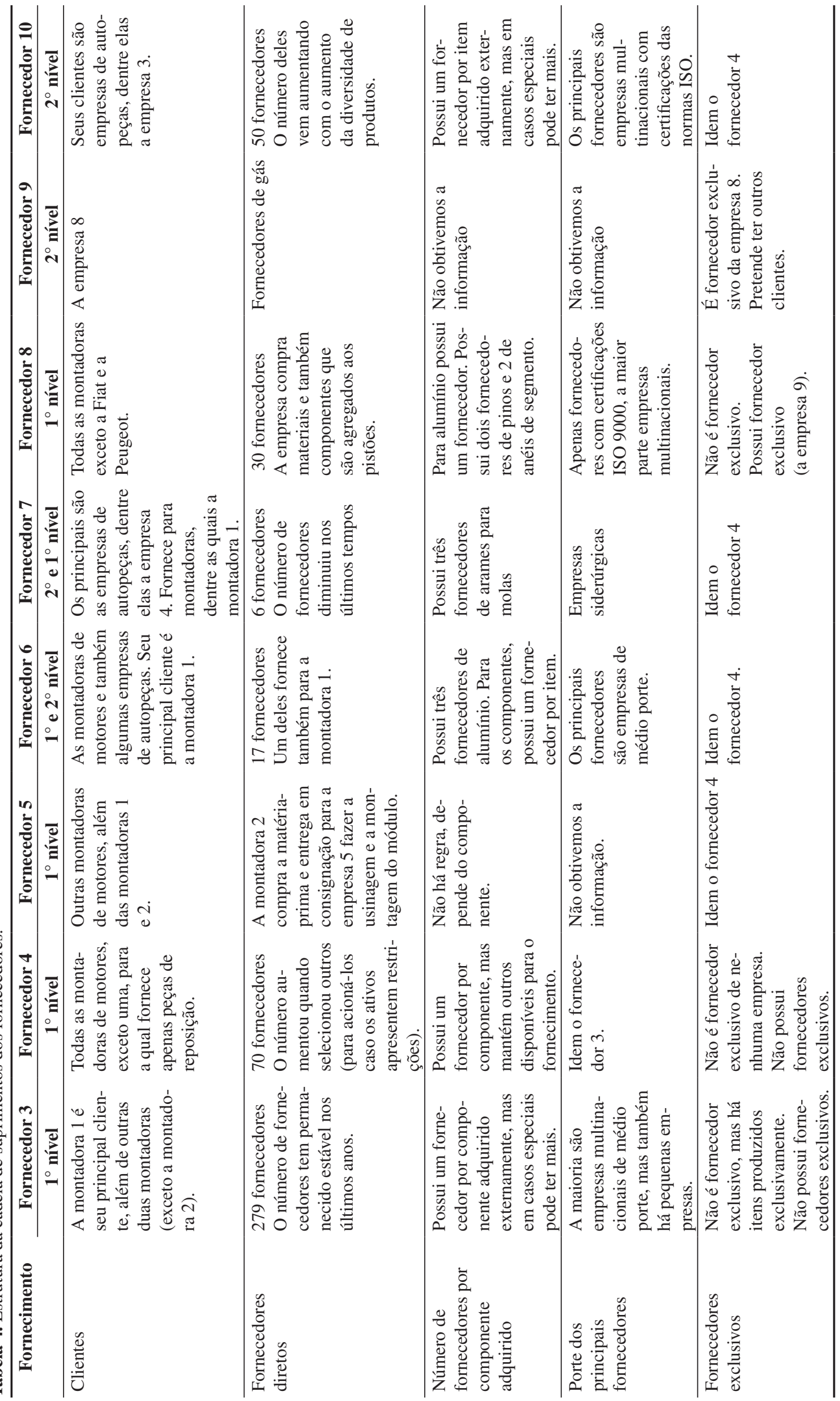




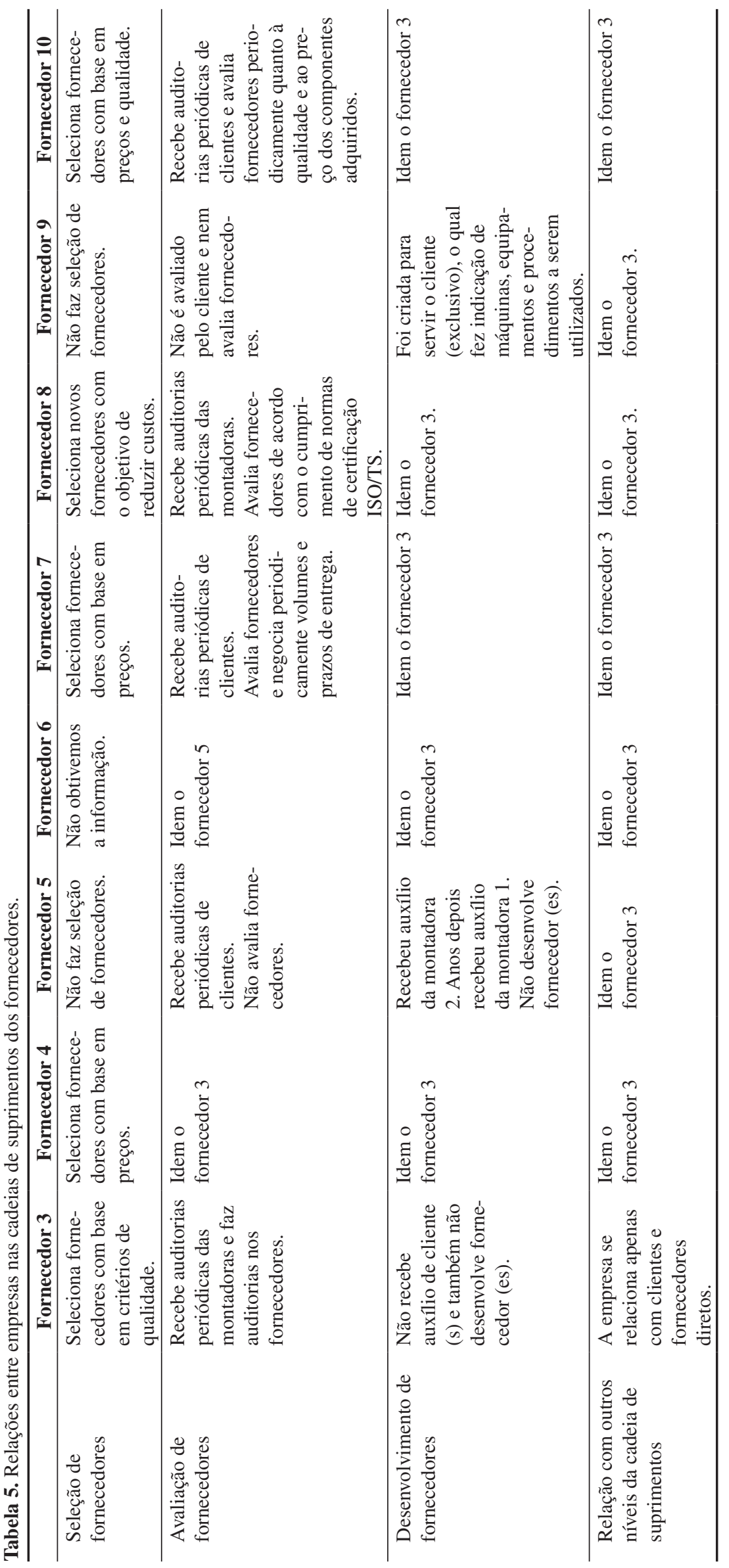


dos componentes para motores. A montadora 3 é a mais terceirizada, a montadora 1 ocupa uma posição intermediária, e a montadora 2 pode ser considerada a menos terceirizada das três, embora recentemente tenha deixado de produzir internamente uma série de componentes.

Segundo Maia (2006), a realização desta parece não ser fator que traga diferencial positivo para as montadoras. Ao contrário, a não terceirização acarretaria malefícios, dado que os fornecedores desenvolveram know-how sobre o produto, em muitos casos, superior às próprias montadoras.

Assim, não terceirizar a produção de determinados componentes implicaria possivelmente em deixar de ter contato com os últimos desenvolvimentos presentes na indústria automotiva. Uma vez que praticamente as mesmas empresas atuam no fornecimento de componentes similares para quase todas as montadoras, e os eventuais desenvolvimentos realizados para uma montadora serão repassados para os componentes fornecidos a outras, configurando certa equalização tecnológica dos itens terceirizados.

Verifica-se que a demanda por inovações tecnológicas tem origem na(s) montadora(s), quando essa(s) desenvolve(m) um novo modelo de motor. Durante esta fase as montadoras envolvem, de certa forma, alguns de seus fornecedores diretos, que por sua vez repassam para alguns de seus fornecedores (os fornecedores de segundo nível das montadoras) a necessidade de desenvolverem novos componentes (para motores).

Estas montadoras têm implementado modelos distintos quanto ao número de fornecedores por componente ou peça adquirida. A montadora 1 possui cerca de 80 fornecedores diretos e a montadora 2 possui aproximadamente 100 , sendo que ambas pretendem reduzir o número deles. Ambas pretendem concentrar o fornecimento de cada componente em um único fornecedor, desde que este tenha capacidade de produção suficiente para suprir a demanda da(s) montadora(s). Desse modo, as montadoras 1 e 2 possuem, predominantemente, um fornecedor por componente terceirizado.

Já a montadora 3 possui 130 fornecedores diretos e vem aumentando o número deles, conforme tem aumentado a diversidade de seus produtos. A política de suprimentos desta montadora consiste em ter, predominantemente, dois fornecedores por tipo de componente terceirizado, e deste modo incentivar a concorrência entre eles, aumentando assim seu poder de barganha nas negociações. Para alguns componentes, a montadora 3 possui apenas um; para outros, possui três fornecedores.

Além destas diferenças estruturais verificadas, as cadeias apresentam diferenças quanto ao porte e capacidade tecnológica dos fornecedores que as compõem. Enquanto as montadoras 1 e 2 concentram suas bases de suprimentos em fornecedores de maior porte e capacidade tecnológica, preferencialmente empresas multinacionais e certificadas em normas de qualidade, a montadora 3 embora também possua esse tipo de fornecedores, procura desenvolver um número significativo de empresas pequenas, ou seja, estabelecer programas de treinamento para alguns de seus fornecedores para auxiliá-los a alcançar metas de desempenho superiores.

As montadoras 1 e 2 procuram estabelecer relações de longo prazo com um número menor de fornecedores criteriosamente selecionados, nas quais os fornecedores assumem responsabilidades quanto à tecnologia (na grande maioria dos casos), qualidade, entrega e embalagem dos componentes fornecidos, além dos estoques. Nestes casos, a montadora teria certa dificuldade para substituir um fornecedor, se necessário.

Já a montadora 3 combina tanto relacionamentos similares aos observados entre as montadoras 1 e 2 e seus fornecedores, quanto relacionamentos com empresas pequenas, dependentes da montadora e desenvolvidos por ela em algum momento. E ainda, ao adotar como política de suprimentos a prática de possuir dois fornecedores por componente comprado, procura ampliar seu poder de barganha com os fornecedores, incentivando certa concorrência entre eles e mantendo menor dependência dos mesmos.

Em algumas empresas pequenas, geralmente de capital nacional, a montadora 3 investiu em máquinas e equipamentos, conhecimentos tecnológicos (para produtos e processos de produção), auxiliou na certificação de normas de qualidade e enviou engenheiros à planta destas empresas para pessoalmente ajudarem a implementar as melhorias almejadas. As montadoras 1 e 2, por sua vez, também desenvolveram alguns de seus fornecedores, mas foram casos bastante raros, segundo os entrevistados.

O desenvolvimento de fornecedores não parece ser preocupação principal das montadoras, mas este tipo de suporte parece ocorrer de maneira intensa em alguns casos, quando o desenvolvimento de um fornecedor, por alguma razão, é necessário para as operações da montadora.

A empresa 5 foi desenvolvida pela montadora 3 e só a partir disso obteve outros clientes, dentre os quais a montadora 2, quando esta terceirizou a usinagem dos coletores de admissão. Nesta terceirização, a empresa 5 recebeu a tecnologia e as máquinas necessárias.

Em geral, os critérios utilizados pelas montadoras para selecionar fornecedores são: preço, qualidade e capacidade tecnológica. Enquanto a montadora 3 prioriza o preço, e por conseguinte, coloca qualidade e capacidade tecnológica em segundo plano, as montadoras 1 e 2 priorizam estes dois últimos critérios de seleção.

Quanto aos fornecedores ativos, as três montadoras os avaliam através de auditorias de produtos e de processos, com base em normas de qualidade, e os classifica de 
acordo com o desempenho de cada um deles frente ao cumprimento dos itens exigidos. Nesse contexto, os fornecedores que apresentam problemas recorrentes em seus produtos e/ou processos de produção recebem da montadora um prazo para corrigi-los, dentro do qual uma nova auditoria será feita.

Alguns fornecedores produzem componentes importantes para motores das diversas montadoras de motores. Mas, mesmo com diversos fornecedores comuns, parece plausível a proposição de que, dada a participação de outros tipos de fornecedores no primeiro nível hierárquico, dados os tipos de parcerias que as montadoras adotam com fornecedores, e dadas as políticas de suprimentos que procuram implementar, as montadoras comandam cadeias e impõem padrões de comportamento distintos. Desta forma, embora ocorra certa sobreposição entre as cadeias (pela presença de fornecedores comuns), as montadoras podem efetivamente utilizá-las de forma a aumentar sua competitividade.

De acordo com a literatura de gestão da cadeia de suprimentos, a competição entre cadeias inteiras implica que todos os seus elos constituintes tenham prioridades estratégicas semelhantes em suas operações. Em um outro estudo empírico, Maia et al. (2005) ressaltam que nas cadeias automotivas as prioridades das empresas parecem estar consistentemente alinhadas, dado que tais prioridades refletem exigências do próprio setor industrial, comum a todas as empresas, e ainda, exigências internas a cada elo e relativas ao relacionamento verificado entre as empresas.

Sendo a flexibilidade, segundo Maia et al. (2005), atualmente uma das maiores exigências estratégicas da indústria automobilística, as montadoras atribuem a seus fornecedores de primeira camada parte da responsabilidade em aumentar a flexibilidade e coordenar tal aumento nas camadas inferiores dos fornecedores.

Esta escolha corrobora a proposição de Alves Filho et al. (2000), de que nem sempre será necessário ou vantajoso coordenar todos os elos da cadeia, sendo assim, é importante determinar quais partes da cadeia merecem maior atenção, de acordo com uma série de fatores como as competências da empresa e o nível de importância de cada subconjunto de peças (e seus correspondentes fornecedores) no contexto de negócio.

No que diz respeito às exigências internas às cadeias, conforme já foi mencionado, as montadoras apresentam diferentes prioridades estratégicas, estando a montadora 3 enfatizando custos, enquanto que as demais montadoras estudadas estão mais orientadas a questões de qualidade e capacidade tecnológica dos fornecedores.

Os estudos demonstram que os fornecedores em geral são dependentes das estratégias das montadoras, aceitando exigências quanto a especificações técnicas e qualidade dos produtos fornecidos, além de preços e prazos de entrega dos mesmos. Esta dependência é ainda maior no caso dos fornecedores que foram, em algum momento, desenvolvidos pela(s) montadora(s).

Considerando que os fornecedores principais normalmente atendem várias montadoras e implementam estratégias que necessitam ser compatíveis com a de seus clientes, pode-se afirmar que o conjunto de montadoras, de algum modo, comanda as cadeias de fornecedores, até mesmo no caso de fornecedores de grande porte ou tecnologicamente autônomos. No caso destes últimos, vale ressaltar que muitos deles ocupam papéis importantes nessas cadeias, detendo o know-how relativo a componentes que são considerados estratégicos (sob o ponto de vista tecnológico) para as montadoras, além de apresentarem padrões de desempenho e normas de qualidade em patamares próximos aos delas. Além disso, estes fornecedores tendem a coordenar seus subfornecedores.

\section{Conclusões e considerações finais}

Embora a base de observação empírica possa ser considerada limitada para fazer recomendações sobre GCS, é importante enfatizar que os estudos de caso realizados nas empresas incluíram questões que envolviam tanto os clientes quanto os fornecedores, de forma a cobrir as cadeias de suprimentos.

Comparando as estruturas das cadeias estudadas, verifica-se alto grau de similaridade entre as cadeias das montadoras 1 e 2 . Ambas possuem número similar de fornecedores, adotam a política de um fornecedor por componente e relacionam-se com empresas de grande porte, em sua maioria. A montadora 3 possui grau maior de terceirização, adota a política de ter dois fornecedores (ou mais) por componente adquirido externamente, e possui número maior de pequenas empresas (e menos capacitadas tecnologicamente) na composição da cadeia. Tais diferenças na estrutura da cadeia implicam em certas diferenças nas relações entre as empresas que as compõem.

A montadora 3, com maior número de fornecedores de menor porte e com capacitação tecnológica limitada, deve despender esforço maior para desenvolvê-los e garantir desempenho adequado. Já as montadoras 1 e 2, que possuem proporção maior de fornecedores de grande porte e mais capacitados tecnologicamente, por sua vez, devem despender esforços relativamente maiores nas negociações (das transações) com fornecedores, mas seu esforço para desenvolvê-los seria muito menor.

As decisões parecem estar coerentemente alinhadas no contexto da gestão da cadeia de suprimentos de cada montadora. A montadora 3 enfatiza o preço como principal critério de seleção, utiliza dois fornecedores por componente, de forma a propiciar competição entre eles, e em alguns casos se relaciona com segundo nível da 
cadeia para utilizar seu poder de barganha. As montadoras 1 e 2 enfatizam qualidade como principal aspecto, além de capacitação tecnológica, optando por relações mais estreitas com fornecedores maiores, e com apenas um fornecedor por componente adquirido.

Mesmo ocorrendo sobreposição entre as cadeias, as montadoras conseguem efetivamente utilizá-las de forma a aumentar sua competitividade. Têm-se que os fatores de desempenho competitivo priorizados pelas montadoras, são de alguma forma, importantes fontes de tomada de decisão para as empresas fornecedoras.

Em linhas gerais, montadoras e fornecedores estabelecem parte de seus objetivos estratégicos em função das demandas inerentes ao próprio setor industrial em que estão inseridas. Contudo, diferenças nas cadeias de suprimentos a que estas empresas pertencem, bem como distinções entre as próprias empresas constituintes dos seus elos, colocam sobre montadoras e fornecedores um conjunto de demandas que são internas a cada cadeia, e eventualmente, a cada elo no interior de cada cadeia.

Em decorrência de diferenças nas cadeias de suprimento, embora as empresas adotem prioridades competitivas similares, estas são viabilizadas através de decisões diferentes, mas estrategicamente alinhadas. As montadoras, inseridas em cadeias com configurações estruturais diferentes, e adotando padrões de relacionamento distintos entre empresas, adotam ações para gestão da cadeia de suprimentos, que embora diferentes, buscam viabilizar suas prioridades estratégicas.
Ainda, pode-se concluir que as montadoras, mesmo sob algumas condições semelhantes, se utilizam de diferentes meios para competirem, e que o alinhamento estratégico existe nas três cadeias estudadas, cada uma em função das prioridades competitivas que perseguem. É plausível aceitar também, que os esforços para manter e coordenar este alinhamento devem ser diferentes nos diversos casos, dadas as distinções estruturais e relacionais verificadas em cada cadeia.

São diversas as possibilidades de desdobramentos desta pesquisa. Algumas delas são: a) uma comparação entre todas as cadeias de todas as montadoras de motores instaladas no Brasil, de modo a trazer elementos empíricos adicionais para a comparação entre cadeias; e b) um estudo envolvendo fornecedores de perfil diferente aos aqui retratados: a) outras empresas fornecedoras de capital nacional; b) outros fornecedores do segmento de componentes microeletrônicos; e c) fornecedores de outros segmentos, como por exemplo, o de componentes produzidos com materiais poliméricos. Há informações obtidas em uma das montadoras que indicam a tendência de alguns motores utilizarem coletores de plástico ao invés de alumínio.

Além disso, outras possíveis pesquisas podem buscar aprofundar os elementos aqui retratados, explorando questões com maior riqueza de detalhes, de forma a detalhar como elementos operacionais se combinam no contexto da gestão das cadeias automotivas de suprimentos, bem como estes apóiam as estratégias competitivas e de GCS das empresas. 


\title{
Strategic, structural and relational aspects of three automotive supply chains
}

\begin{abstract}
The aim of this paper is to identify structural, relational and strategic differences among Brazilian engine assembling chains, as well as suggesting factors originating from or responsible for such differences. Thus, the structures of three chains are studied and compared, as well as the relationships that take place. A case study was carried out and it consists of eight suppliers positioned in the first and/or second tiers of their chains, as well as the three engine manufacturers. Although the engine manufacturers belong to chains with distinct structural configurations and adopt different relationship patterns, their decisions regarding supply chain management are strategically aligned. Thus, although some overlapping among the chains occurred, the automakers succeeded in effectively using them to improve competitiveness. The work also indicates some general trends that were observed, such as the increase in the outsourcing level, and the existence of few hierarchical levels, consisting of, in the second tier, suppliers of less technologically sophisticated products.
\end{abstract}

Keywords: Supply chain management. Strategy. Automotive industry. Automotive engine.

ALVES FILHO, A. G. et al. Uma tentativa de integração das estratégias de produção e tecnológica. In: ENCONTRO NACIONAL DE ENGENHARIA DE PRODUÇÃO, XXV., 2005, Porto Alegre. Anais... Porto Alegre, RS, Brasil. p. 3588-3595.

ALVES FILHO, A. G. et al. Pressupostos do Gerenciamento da Cadeia de Suprimentos: evidências de estudos sobre a indústria automobilística. Gestão \& Produção, São Carlos, v. 11, n. 3, p. 275-288, set-dez, 2004.

ALVES FILHO, A. G. et al. Supply Chain assembler control: the case of Volkswagen's engine plant of São Carlos-SP-Brazil. In: RENCONTRE INTERNATIONALE DU GERPISA, 8., 2000 Paris.

CERRA, A. L. Estratégias Tecnológicas em cadeias de suprimentos da indústria automobilística brasileira: estudos de caso em empresas do segmento de motores de automóveis. 2005. 214 f.. Tese (Doutorado em Engenharia de Produção) - Departamento de Engenharia de Produção, Universidade Federal de São Carlos, São Carlos-SP, 2005.

CHOPRA, S.; MEINDL, P. Gerenciamento da Cadeia de Suprimentos - Estratégia, Planejamento e Operação. São Paulo: Prentice Hall, 2003.

CHRISTOPHER, M. Logistics and supply chain management. London: Pitman Publishing, 1992.

COOPER, M. C.; LAMBERT, D. M.; PAGH, J. D. Supply chain management: more than a new name for logistics. The International Journal of Logistics Management, v. 8, n. 1, p. 1-13, 1997.

ELlRAM, L.; BILlingTON, C. Purchasing leverage considerations in the outsourcing decision. European Journal of Purchasing \& Supply Management, v. 7, p. 15-27, 2000.

HANDFIELD, R. B. et al. Avoid the pitfalls in supplier development. Sloan management Review. v. 41, n. 2, p. 37-49, Winter, 2000.
LAMMING, R. Beyond partnership - strategies for innovation and lean supply. United Kingdon: Prentice Hall, 1993. 299 p.

LAZZARINI, S. G. Estudos de caso: aplicações e limites do método. In: FARINA, E. Estudos de caso em agribusiness. São Paulo: Pioneira, 1997.

LUMUS, R. R.; VOKURKA, R. J. Defining Supply Chain Management: a historical perspective and pratical guidelines. Industrial Management \& Data Systems. v. 99, n. 1, p. 11-17. 1999.

LUMUS, R. R.; VOKURKA, R. J.; ALBER, K. L. Strategic supply chain planning. Production and Inventory Management Journal, v. 39, n. 3, p. 49-58, 1998.

MAIA, J. L. Alinhamento entre a Estratégia de Operações e a Gestão Estratégica da Logística: Estudos de caso no setor automotivo brasileiro. 2006. 230 f.. Dissertação (Mestrado em Engenharia de Produção) - Departamento de Engenharia de Produção, Universidade Federal de São Carlos, São Carlos, 2006.

MAIA, J. L.; CERRA, A. L.; ALVES FILHO, A. G. Interrelações entre Estratégia de Operações e Gestão da Cadeia de Suprimentos: Estudos de Caso no segmento de motores para automóveis. Gestão \& Produção. v. 12, n. 3, p. 377-391, setdez. 2005.

MIRANDA, J. L. Procedimento para análise da viabilidade da utilização de operadores logísticos na cadeia de suprimentos. 2006. Tese (Doutorado em Engenharia de Produção) - Escola de Engenharia de São Carlos, Universidade de São Paulo/ USP, São Carlos, 2002.

PEDROSO, M. C. Um estudo sobre o desenvolvimento de competências em Gestão de Cadeia de Suprimentos. 2002. 342 f.. Tese (Doutorado em Engenharia de Produção) - Escola Politécnica, Universidade de São Paulo. São Paulo, 2002. 
PIRES, S. R. I. Gestão da Cadeia de Suprimentos (Supply Chain Management) - Conceitos, Estratégias e Casos. São Paulo: Atlas, 2004. 310 p.

QUADROS, C. R. et al. Globalização e reestruturação da cadeia produtiva na indústria automotiva: qual é o papel do Mercosul? Campinas: Convênio IPEA-DPCT/IG/UNICAMPFUNCAMP, 2000 (Série Texto Técnico).
SLACK, N. et al. Administração da Produção. São Paulo: Atlas, 1997.

TAN, K. C. Supply Chain Management: Practices, concerns, and performance issues. The Journal of Supply Chain Management - A Global Review of Purchasing and Supply. p. 42-53, Winter, 2002.

\section{Sobre os autores}

\section{Aline Lamon Cerra \\ Jonas Lucio Maia Alceu Gomes Alves Filho}

Departamento de Engenharia de Produção, Universidade Federal de São Carlos - UFSCar, Rodovia Washington Luís, Km 235, CP 676, CEP 13565-905, São Carlos, SP, Brasil,

e-mails: alinelc@ terra.com.br; jonasmaia@dep.ufscar.br; alceu@ power.ufscar.br 
